\title{
Main Features and Challenges of Implementing Internal Quality Assurance Within African Higher Education Institutions: The Case of Eduardo Mondlane University
}

\author{
Nelson Casimiro Zavale, Luisa Alcantra Santos, \\ and Maria da Conceição Dias
}

\begin{abstract}
Founded in I962, Eduardo Mondlane University (UEM), Mozambique's largest and most prestigious university, established an Internal Quality Assurance (IQA) system for the first time in 20I3. Based on UEM's case, this paper examines the features and challenges faced when implementing an IQA system within African higher education institutions. Literature on higher education quality assurance has widely examined the features of, and challenges faced by national QA systems, or by a QA system established across several higher education institutions (HEIs). However, this literature has rarely targeted single HEIs, particularly (African) HEIs that are establishing, for the first time, their IQA systems. Besides, even when IQA at a single HEI is targeted, this is often done by outsiders. Based on reflection-in-action and reflection-on-action, this paper addresses the perspectives of both insiders and outsiders. The authors analyse a system that they have been involved in establishing. The paper's findings enable to conclude that the main challenges of implementing an IQA system in an African HEI are associated with linking QA to decision-making and to a funding strategy; training human resources and allocating funds for the system to operate and to be sustainable; enabling the system to be assimilated by the university community; and defining measurable and objective quality standards to enable unbiased performance classification.
\end{abstract}


Key Words: Internal Quality Assurance, Eduardo Mondlane University, Mozambique

Fondée en I962, l'Université Eduardo Mondlane (UEM), la plus grande et la plus prestigieuse université du Mozambique, a créé pour la première fois en 2013 un système interne d'assurance qualité (IAQ). A partir de l'étude du cas de l'UEM, cet article examine les caractéristiques et les défis qui attendent les institutions d'enseignement supérieur africaines qui désirent implémenter un IAQ. La littérature sur l'assurance qualité de l'enseignement supérieur a largement examiné les caractéristiques des systèmes nationaux d'AQ (ou de systèmes communs à plusieurs institutions), et les défis auxquels ils sont confrontés. Elle s 'est cependant rarement concentrée sur des cas uniques d'institutions, notamment des institutions (africaines) qui ont créé pour la première fois leur propre IAQ. Par ailleurs, même quand elle s'attarde sur une institution en particulier, l'analyse est souvent effectuée par des personnes étrangères à l'institution. Fondé sur la réflexion dans l'action et la réflexion sur l'action, cet article présente les perspectives de personnes internes et étrangères à l'établissement. Il permet de conclure que les principaux défis à affronter lors de l'établissement d'un IAQ sont dus à la difficulté de lier l'AQ à la prise de décision et à une stratégie de financement ; à la formation des ressources humaines et l'allocation des fonds nécessaires pour que le système fonctionne et perdure ; à l'assimilation du système par la communauté universitaire ; et à la définition de standards de qualité mesurables et objectifs pour permettre une classification de la performance impartiale.

We are grateful for the support received from UEM's rector, vice-rectors and faculty deans. We also thank the heads of departments, academic programmes directors, quality coordinators and ad-hoc commissions for conducting the self-assessment and for implementing the system at faculty level. Special gratitude is owed to students, graduates and employers for participating in the survey, and to the National Council for Quality Evaluation (CNAQ) for technical support. Lastly, we thank the Italian Project for the funding, and two anonymous reviewers for their valuable comments.

\section{Introduction}

The idea that the services provided by higher education institutions (HEIs) should be subjected to quality control is not new. The quality issue has been a permanent concern of the academic ethos since early universities (Van Vaught, 1995). What is new is the centrality of the quality issue as a key higher education (HE) steering policy. Since the I980s, developed countries have established systematic quality policies. Several factors accounted for this policy shift, including (i) massification of HE; (ii) loss of confidence on the capacity of HE to maintain high standards and meet the demands of a competitive labour market; (iii) decline in government funding and increasing demand for accountability of HE; (iv) rapid growth of HE private sector and emergence of new public management; and (v) increasingly competitive HE system (Van Damme, 2002; Rosa and Amaral, 2007). In Africa, the quality issue as a key national HE steering policy is also a new phenomenon: the majority of quality assurance (QA) agencies were established after I990s. By 20I2, about 2I African countries had established QA agencies, and a dozen other countries were moving in this direction (Shabani et al. 20I4).

The establishment of QA systems at international, national and institutional levels led scholars to examine the features and challenges of these systems. This interest provided useful analyses on the main features of QA systems established worldwide (Van Vught and Westerheijden, I994; Vroeijenstijn, I995; Stensaker, 2003; Kis, 2005; Westerheijden et al. 2007). In Africa, such an effort was undertaken by Materu (2007) and Shabani et al. (2014). Research seems to have focused on cross-national or national QA systems, rather than on institutional systems. The features of QA systems established within HEIs have often been examined as part of national or regional systems, but few studies have focused on internal QA (IQA) systems established within single HEIs (Rosa and Amaral, 2007; Sursock, 20II; Nguyen, 20I2; Adamu and Adamu, 20I2). Studies on IQA systems have often targeted several HEIs, but rarely single HEIs. While targeting national QA systems is useful in depicting the regular properties of the different systems established across countries and HEIs (allowing to have a picture of a forest), it may overlook specific features and challenges faced by IQA systems established within single HEIs (allowing to have a picture of a single tree).

This paper examines the IQA system of Eduardo Mondlane University (UEM), the oldest and arguably most prestigious Mozambican HEI. Established in 1962 in the Portuguese-colonial period, it has undergone many changes similar to those of other African HE systems, namely an increase in enrolments vs. funding constraints, the emergence of privately paid academic programmes, and a diversification of academic programmes (Langa, 20I4b). In 20I2, 50 years after its establishment, the first IQA system was approved, and it was implemented for the first time in 20I3. This paper seeks to provide an analysis of the features 
and challenges faced in establishing an IQA system within an African HEI. The paper's contribution is also methodological. Most analyses on QA systems are done by outsiders, particularly by HE scholars. In this paper, the analysis and evidence are drawn from our reflection-in-action and reflection-on-action (Schön, I983) when establishing and running the programme. To insert the Mozambican case into the African context, the paper begins by describing ongoing trends and challenges of QA systems in Africa.

\section{QA in Africa}

Before independence, the quality of African HEIs was maintained by their European counterparts, within an "affiliation" framework (Materu, 2007:I5). After independence, particularly during the I980s, the quality issue was generally neglected, as was the whole HE sector in Africa. Except for some countries, such as Nigeria and Kenya, which established national QA systems in the I960s-I980s, the quality issue as a key HE steering policy is a new phenomenon in Africa. About 70 percent of QA agencies were established since I990s (Materu, 2007:20; Shabani et al. 20I4:I50).

The shift towards establishing QA systems is associated with the need to cope with ongoing transformations of the African HE sector: rapid growth vs. funding constraints; demands for accountability; privatisation; perceptions of decline in quality; the emergence of the knowledge economy and the repositioning of $\mathrm{HE}$ at the heart of developmental strategies; demands for more relevant HE; internationalisation and efforts towards continental harmonisation of $\mathrm{HE}$ (Hayward, 2006; Materu, 2007; Mohamedbhai, 20I4; Shabani et al. 20I4). As mentioned above, by 20I2, about 2I African countries had governmentally-established QA agencies and others were moving in this direction. Only few of these national agencies are semi-autonomous, the majority being controlled by governments regarding their management, funding and decision-making (Materu, 2007:19-20). Overall, their mandate consists of assessing HEIs and programmes according to pre-established quality standards and criteria, as well as approving the creation of new programmes and HEIs. To fulfil this mandate, these agencies often go through similar processes used worldwide by QA agencies: (i) self-assessment and report writing; (ii) external assessment through peer-review, site visit and reports analysis; and (iii) accreditation. As a rule, self-assessment is conducted internally by HEIs, and external assessment and accreditation are conducted by external constituencies, under the supervision of national QA agencies (Materu, 2007). But in some countries such as Ethiopia,
HEIs may internally accredit programmes (Adamu and Adamu, 20I2). Before the establishment of national QA agencies, African HEIs used other QA mechanisms, which included scrutinising the quality of inputs (students, academic staff, facilities, funding, etc.), processes (curriculum, teaching-learning methods, institutional policies) and outputs (graduates and research). QA was often undertaken by internal boards, as well as by external constituencies, particularly external examiners. The other often-used mechanism was institutional academic reviews, i.e. ad-hoc commissions set up to evaluate particular institutional sectors and suggest recommendations. However, according to Materu (2007), little is known on the effectiveness of these unsystematic and often short-term mechanisms. Many African HEIs still lack internal permanent academic units devoted to quality issues, as referred by Materu: "Although many institutions claim to pay attention to quality issues, few actually have in place dedicated units that can monitor performance and advise management on a regular basis" (2007:34). This contrasts with the key function of IQA units for institutional capacity-building and improvement. Since Materu's report in 2007 , little research has been done regarding the functioning of IQA units within African HEIs.

Available literature provides evidence of the establishment of permanent IQA units and directors/coordinators within some African HEIs, such as the University of Mauritius (Materu, 2007), the University of Namibia (Bull et al. 20I2), Kwame Nkrumah University of Science and Technology in Ghana (Materu, 2007), Kenyatta University in Kenya (Lananès et al. 20I2) and the University of South Africa (Mabuza, 20I4). There is also evidence of establishment of QA units within private HEIs in Ghana and Nigeria (Odukoya, 20I5; Ntim, 20I4). In other institutions, quality departments are in the process of being established, as at Ahmadu Bello University in Nigeria (Müller et al. 20I2). However, there are still cases in which self-assessment is undertaken by ad-hoc committees, like at Bahir Dar University in Ethiopia (Adamu and Adamu, 20I2) and at the University of Cape Town, Rhodes University, and Stellenbosch University in South Africa (Botha et al. 2008).

Both at national and institutional levels, the implementation of QA in Africa entails many challenges. From the literature review, we identified seven main challenges. The first is the high cost of QA vs. insufficiency of funds. Governments and donors have often supported the burden of $\mathrm{QA}$, but the question concerning who should pay (whether the government, the HEIs themselves, the private sector or donors) is far from being resolved. The financial concern is challenging for national and institutional QA systems. At the institutional level, HEIs budgets hardly include QA activities. The second challenge is the lack of qualified staff 
in QA issues, including members of peer-review panels with adequate academic-professional profile. This challenge is associated with doubts on the legitimacy of QA. It is often challenging to accept and consider QA as a useful process, if the expertise of the personnel involved is questioned (Odhiambo, 2014; Materu, 2007; Hayward, 2006). The third challenge concerns the participation of different stakeholders in the process, particularly external constituencies, such as professional bodies and employers; but, in some circumstances, the involvement of internal stakeholders, particularly students, is ineffective, as in some private universities in Ghana (Ntim, 20I4). The fourth challenge is the lack of autonomy: the financial dependency of national QA agencies on governments makes them susceptible to political interference (Materu, 2007; Hayward, 2006); likewise, the dependency of IQA units on the senior leadership may undermine their improvement and accountability missions (Adamu and Adamu, 20I2). The challenge of autonomy is exacerbated by the perception that national QA agencies oversee private HEIs, whereas public HEIs may be exempted from control (Ogachi, 2009). The fifth challenge is the definition of quality standards and criteria that, while not overlooking the global trends in HE benchmarking and rankings, are grounded on African context. Overall, there is a feeling that the standards and criteria devised at international level, most of them based heavily on research, need to be adjusted to the African context (Okebukola, 2015:22-23). The sixth challenge is the need for continental and regional harmonisation of the diverse national QA systems and practices. In that regard, many initiatives have been undertaken, such as the African Quality Rating Mechanism and the Europe-Africa Quality Connect Project, but the African space of QA is still far from being interconnected (Okebukola, 2015; Shabani et al. 20I4, Ogachi, 2009). The seventh challenge concerns decision-making based on the results of quality assessment. With regard to accountability, the results from assessment may lead decision-makers to accredit, or not, institutions or programmes and, in some circumstances, to close them. With regard to improvement, the results may provide valuable data on institutional areas that need more investment. While some countries have begun using QA systems as steering mechanisms, in other countries decision-makers still overlook, or lack the knowhow on what to do with the information gathered through QA. For example, the team that visited Kenyatta University under Europe-Africa Quality Connect Project, found out that the university had a lot of information about its performance, but there were no reliable insights concerning the actions taken as a result (Lananès et al. 20I2:I3). There is still no link, for example, between QA and allocation of funding (Materu, 2007).

\section{Establishment of a QA System in Mozambique}

Like other African countries, Mozambique established its QA system during the 2000 s. The need for a national QA system was first acknowledged by the HE strategic plan 2000-20IO and prescribed in the HE law No. 5/2003, in response to the transformation of the country's HE system (Langa, 20I4a). Since the mid-I99os, Mozambican HE has experienced many of the transformations that also occurred in other international and African HE systems: rapid expansion and diversification, growth of private HEIs, funding constraints, and demands for accountability (Langa, 20I4b). From I975 (the year of independence) until I994, Mozambique had only 3 HEIs, with less than 4,000 students. But from I995 to 20I4, the number of HEIs reached 46 (I8 public and 28 private) (Langa, 20I4b), and the number of enrolled students increased to 130,000 (UNESCO Institute for Statistics, 20I5). The rapid expansion and diversification of HEIs has been driven by (i) the shortage of qualified personnel and limited opportunities to attend HE vs. a high demand for university diploma holders; (ii) the introduction of new HE legislation establishing non-governmental HEIs; (iii) the creation of new, professional HEIs (Mário et al. 2003).

Thus, it was urgent to establish QA mechanisms to cope with the rapid expansion, diversification, funding challenges, relevance and accountability concerns of Mozambican HE, as well as to meet regional and international standards (Langa, 20I4a). But it was only in 2007 that the National System of Evaluation, Accreditation and Quality Assurance of Higher Education (SINAQES) was approved by the Council of Ministers and established (Decree No. 63/2007, of $3 \mathrm{I}^{\mathrm{st}}$ December). SINAQES sets up rules for the QA system and establishes an agency for implementing those rules - the National Council for Quality Evaluation (CNAQ). The mandate of SINAQES includes: (i) developing and promoting the principles of culture of systematic QA of HE services; (ii) identifying, developing and implementing standards and quality indicators; (iii) informing society about the quality of teaching in HEIs; (iv) identifying HE problems and outlining mechanisms to solve them, and defining policies for the sector; and (v) contributing to the regional and international integration of Mozambican HE. These functions show that SINAQES has primarily been developed to enhance improvement rather than accountability. Opting for improving the quality of HE services is justifiable given the early stage of the Mozambican QA system. As in other QA systems examined above, SINAQES targets the assessment of institutional and academic programmes and comprises self-assessment, external assessment and accreditation. Although established in 2007 , CNAQ, as other African QA agencies, is not yet fully 
resourced. According to Langa (20I4a: 22), by 20I3, only 50 percent of the 53 staff, most of them unqualified, had their contracts legally recognised. Financially, CNAQ relies on state budget and international donors. Langa (20I4a: 23) considers this situation a threat to CNAQ's financial stability, operational continuity and independence.

Table 1. CNAQ's financial situation

\begin{tabular}{|l|c|c|c|c|}
\hline Sources & $\mathbf{2 0 1 0}$ & \multicolumn{1}{|c|}{2011} & \multicolumn{1}{c|}{$\mathbf{2 0 1 2}$} & \multicolumn{1}{c|}{$\mathbf{2 0 1 3}$} \\
\hline State budget (MZN) & 272,665 & $3,000,000$ & 30,866790 & $38,438,060$ \\
\hline World Bank (USD) & - & 150,000 & 350,000 & 200,000 \\
\hline $\begin{array}{l}\text { Nuffic-NICHE } \\
\text { (Netherlands government) } \\
\text { (EUR) }\end{array}$ & 50,000 & 58,800 & 689,716 & 226,391 \\
\hline
\end{tabular}

Source: CNAQ (2013), quoted in Langa (2014a: 22)

Besides, CNAQ faces the challenge of autonomy, as other national QA agencies in Africa (Materu, 2007; Hayward, 2006). Initially, the idea was to establish a completely autonomous institution, where the president would be appointed by the head of state and be accountable only to the parliament. But the laws approved after fierce discussions made CNAQ a dependent agency: its president is appointed by the prime minister and its members by the minister in charge of HE. In this framework, the autonomy of CNAQ is undermined by the fact that it is directly accountable to the minister (Langa, 20I4a: 24). This national context has underpinned the process of establishing UEM's IQA system. In order to examine the features and challenges of developing such a system, a conceptual framework is proposed.

\section{Conceptual Framework}

Despite various perspectives regarding the concept of QA (see Kahsay, 20I2:33-34), scholars seem to view $Q A$ as a structured and planned set of policies, processes, procedures and actions designed to assess, maintain and improve the quality of HEIs (Vroeijenstijn, I995; Campbell and Rozsnyai, 2002, Unesco, 2004). Vlãsceanu et al. (2007) rightly warn that QA should not be restricted to other related quality processes, such as quality management, quality control, quality enhancement and quality assessment. According to Vlãsceanu et al. (2007:74), QA is a comprehensive concept: it embraces all policies, processes and actions implied in the terminologies related to evaluation of HEIs for quality improvement and accountability. This set of policies and processes are normally set up at internal and external levels, resulting in Internal Quality Assurance (IQA) and External Quality Assurance (EQA) systems.

IQA is established within the HEIs, while EQA is established above/between HEIs. As highlighted by Dill (2007) quoted in Kahsay (20I2:39), IQA refers to practices used by HEIs themselves to monitor the quality of their education, whereas EQA refers to supra-national or national practices used by external bodies to assure the quality of HEIs and programmes. IQA is often conducted by HEIs themselves, aiming primarily at quality improvement and developing a culture of quality, whereas EQA is undertaken by external bodies, particularly (supra) national QA agencies, aiming at verifying the degree to which HEIs fit a specific purpose or meet pre-established standards. Thus, IQA is often viewed as fundamentally driven towards improving HEIs, while EQA, towards making them accountable (Kahsay, 20I2). However, the boundary between them may be blurred: IQA may also aim at accountability; likewise, EQA may contribute to quality improvement. Indeed, the exclusiveness of each of these systems to one purpose is a matter of vivid academic debates. Some scholars conceive IQA and EQA as having incompatible purposes: the first aims exclusively at improvement and the second, at accountability (Vroeijenstijn, I995; Westerheijden et al. 2007). Other scholars challenge this view, by arguing that IQA and EQA are closely linked and may aim at both improvement and accountability (Stensaker, 2003). Whatever merit each position may have, both agree that IQA is established inside and owned by HEIs, whereas EQA is established above/between HEIs by external agencies. There is also an agreement that both comprise a set of structured policies, processes, procedures and actions designed to assess, maintain and improve the quality of $\mathrm{HE}$.

This concept of QA is a relevant starting point for analysing the features and challenges of the newly implemented IQA system within UEM. The concept provides insights on relevant elements that need to be considered when examining an IQA system: policies, structures, processes, procedures and actions. Although referred to with different terminologies, these elements are present in specific frameworks devised to examine the key features of a QA. For example, Van Damme (2002) identified the following features of QA system: purpose; agency responsible for QA; level of participation; methodology; focus on research or teaching; reports and decision-making as a consequence of QA results. Perellon (2007) proposed a five-dimensional framework: objectives (improvement or accountability); control (bodies controlling the QA); areas covered by QA (research, study programmes and institutional management); procedures; and uses (decision-making 
based on information collected). These frameworks have been produced through cross-national analyses of QA systems of developed and developing countries. Overall, studies have targeted whole (supra) national QA systems and they have analysed IQA systems of HEIs a part of the broader systems. Few studies have focused exclusively on IQA systems developed within HEIs (Rosa and Amaral, 2007; Loukola and Zhang, 20I0; Sursock, 20II; Nguyen, 20I2). While frameworks developed through a national QA system may be useful to examine an IQA system, they need to be combined with those exclusively developed for IQA.

Rosa and Amaral (2007:I95) suggested a seven-dimensional model for examining the process of self-assessment, namely (i) leadership; (ii) policy, strategy, and culture; (iii) actors; (iv) structure and organisation (v) resources and partnerships; (vi) processes; and (vii) results. Loukola and Zhang (20IO) and Sursock (20II) have also proposed elements to consider when examining an IQA: governance, structures and roles; participation of stakeholders; tools and processes used; areas covered; use of information. Based on the concept proposed by several scholars (Vroeijenstijn, I995; Martin and Stella, 2007, quoted in Nguyen, 20I2), Nguyen (20I2) has developed a bi-dimensional model for examining the implementation of IQA within Vietnamese HEIs. The first dimension is how an IQA process is implemented, and this includes examining the linkage between QA and institutional goals, monitoring and evaluation instruments, and improvement plans. The second consists of examining the structure and function of QA units established within the university. Based on these frameworks, we propose a model for examining the features and challenges of the newly implemented IQA system at UEM. As figure I portrays, our model comprises four components:

- Policies: used to examine the objectives, strategies and policies prescribed to UEM's IQA system, and the challenges faced when implementing these strategies.

- Structure and resources: applied to analyse the position of the IQA unit within UEM's organisational structure, as well as the human and financial resources allocated for the functioning of the system. This component is also used to examine the challenges underlying the IQA unit's position, and the challenge faced as a result of the resources provided.

- Procedures and processes: Procedures are used to examine the nature of - and the challenges implied by - the tools used for quality assessment, including the standards and tools used for data collection and analysis, and areas targeted by the evaluation. Processes are used to examine the steps followed throughout the

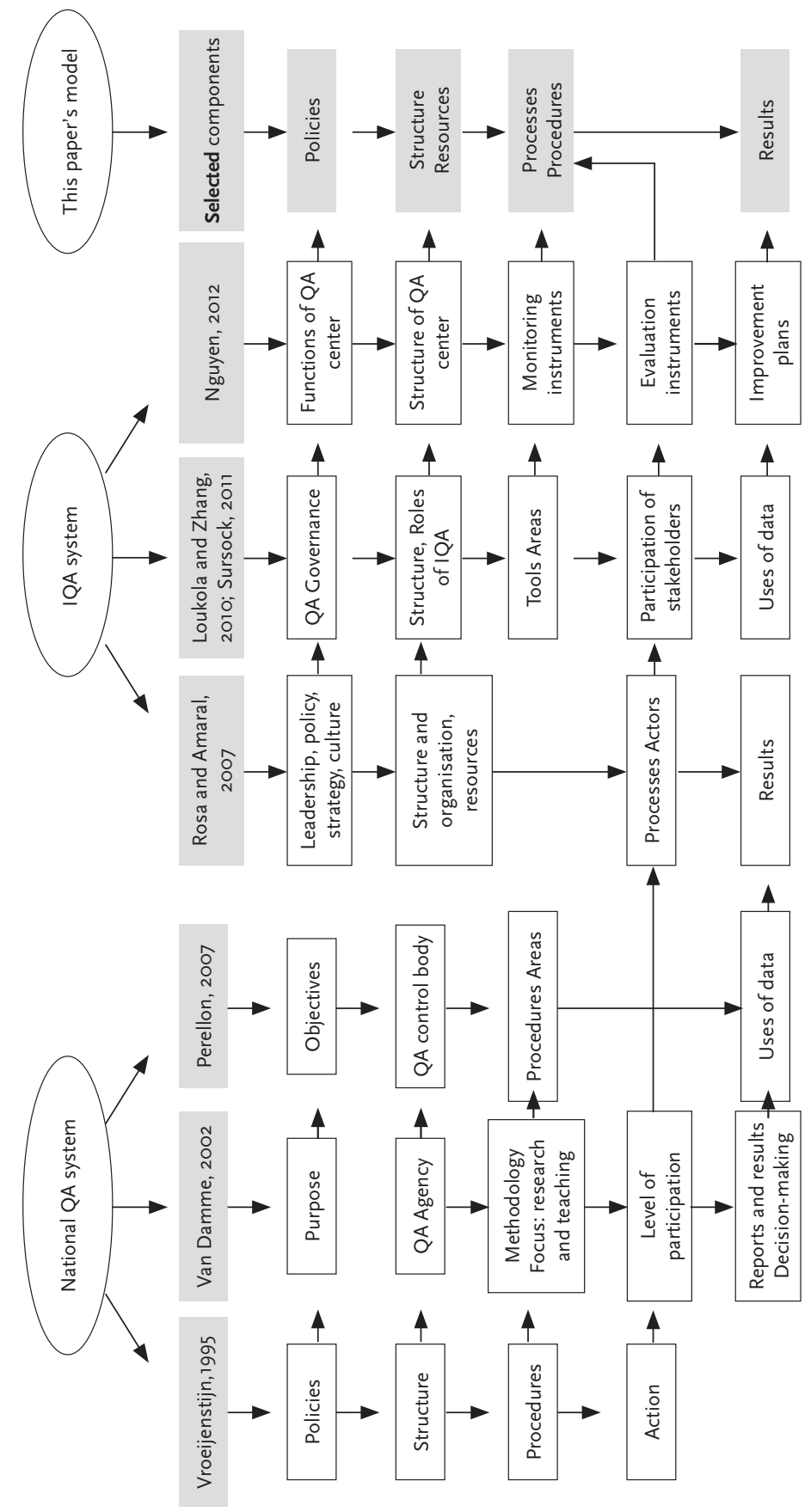


implementation and the participation of different stakeholders.

- Results: used to examine the results depicted by reports concerning the stage of quality of UEM academic programmes. The challenges concerning the use of results for decision-making are also examined.

The model proposed below draws from international literature on QA. But specific QA models have also been proposed in Africa. As referred above, one of the challenges faced by African QA systems is the establishment of standards and criteria that take into account the African specificity. More often, quality standards at international level have been influenced by benchmarking and ranking systems that often emphasise the research dimension of HEIs, to the detriment of teaching and outreach. At international level, the biased nature of the ranking systems has been denounced, resulting in alternative systems proposing holistic approaches, such as the U-Multirank framework suggested in Europe (Van Vaught and Ziegele, 20I2). In Africa, a holistic framework was proposed by Shabani et al. (20I4) and Okebukola and Shabani (2007). These scholars argue that QA in African HE should be based on input-process-output indicators of the teaching, research and outreach mission of HEIs. Inputs are resources allocated to HE (students, teachers, infrastructure, funding, etc.); processes are different ways of managing resources (teaching-learning, administration, etc.) to get the desired outputs; outputs are final product of the HE activity (graduates, socio-economic development and research outputs). Okebukola and Shabani (2007) suggest that, given the diverse and incipient nature of African HE systems, national QA systems should identify the specific elements of inputs, processes and outputs to be covered by QA and define the minimum standards for each element. The minimum standards would then be used as a basis for a harmonised continental framework (Shabani et al. 20I4). The policy-structure-procedures-results framework, portrayed in figure I, is relevant to examine the features and challenges faced by UEM's IQA system as a whole, while the input-process-output model is relevant to examine its components, particularly the challenge of defining minimum standards for each of these components.

\section{Methodology}

As mentioned above, our role was twofold. The first was that of insiders. We are members of UEM's central IQA unit, one of us acting as director, and the other two as scientific-technical supporting staff. As insiders, we have been involved in the conception and establishment of the relevant tools and processes of UEM's IQA system. In addition to our involvement at the central IQA unit, we have also participated in the establishment of the system within our academic departments, where we belong as academics. The second role is that of analysts: trying to balance our insiders' and outsiders' perspectives, we have attempted to remain neutral when examining the features of UEM's IQA system. This paper is a result of this effort. Aware of the limitations of our common-sense knowledge, we have applied an analytical framework to reflect on the features and challenges of UEM's IQA.

Our role as insiders was clearly crucial in getting data with minimum difficulty; however our academic reflection on these data was possibly impaired by our being actors in that same system. The application of reflection-in-action and reflection-on-action approaches (Schön, I983) proved to be useful in dealing with this dual role. As actors, both at the central unit and at our departments, we have not only participated in the establishment of the IQA system, but we have also devoted time to reflect on the significance of each step taken. This reflection-in-action has helped us to produce the tools and data for the IQA system to work, as well as to search for meaning and coherence for each tool and data produced. As analysts and "reflectors-on-action", at the end of the first two years of implementation of the system (20I3-20I4), we disregarded our role of actors to think conceptually about what we had done. This paper is a result of our reflection-on-action. The reflection-in-action and reflection-on-action approaches, part of our dual role, enabled us to get evidence on the features and challenges of UEM's IQA system, considering the four components of our model. Each of the four components implied examining specific evidence:

- For policies, we examined official documents approved by UEM bodies concerning the objectives, strategies and policies prescribed to UEM's IQA.

- For structure, we relied on approved documents and on our knowledge concerning the position of the IQA unit within UEM's organisational structure;

- for human resources, we relied on the characteristics of personnel ascribed to the system; for financial resources, we used statistics on funds allocated to the system.

- For procedures, we examined two documents drafted for orienting the assessment: the CNAQ' manual (CNAQ, 20I3) and UEM's selfassessment manual for programmes (UEM, 20I4). For processes, we examined the final report written on the whole process (Santos et al. 20I4).

- For results, we relied on the global report that we had prepared, as well as on the improvement plans written by eight faculties. 


\section{Findings and Analysis}

Our analysis of the main features and challenges of UEM's IQA system is divided into four subsections, drawn from the four-dimensional model.

\section{Policies}

In this subsection, we examine the characteristics of the policies prescribed to UEM's IQA system and resulting challenges. By policies, we mean the origin of the idea of establishing an IQA, the objectives established and the strategies to attain them. Two relevant documents were examined: the documents establishing both the IQA system and IQA unit, approved by the University Council (UEM, 20I3, 20I2). These documents allow us to validate the idea that the establishment of an IQA system was both internal and external. Internally, the quality issue has always been a permanent concern within UEM. Before the establishment of an IQA system, quality concerns were handled by academic councils and other departments at university and faculty levels. However, quality concerns were not their unique functions; they did not handle quality concerns in a holistic way and specific quality standards were not used.

The practice of handling quality issues in an unsystematic way is not exclusive to UEM. Materu (2007) found out that in Africa, before the establishment of national QA systems - and in countries where agencies are not yet established -, other mechanisms were used to guarantee the quality of students and staff, the teaching-learning process, and the graduates and research outputs. But these mechanisms were unsystematic and their effectiveness is unknown. At UEM, the absence of permanent units for strategic data collection and analysis led the leadership to create various ad-hoc commissions to evaluate particular institutional affairs. But as Materu (2007) emphasised, ad-hoc commissions are undermined by their short-term mandate.

The need of a specific structure to deal exclusively and systematically with quality issues may have driven UEM's leadership to set up an IQA system. Three key factors may have been responsible for the establishment of the IQA system, two external and one internal. The first external factor was the approval, at governmental level, of laws establishing both a national QA system and a national agency. Besides their compulsory nature, the fact that these laws provided parameters and guidelines for the establishment and functioning of a QA system triggered UEM's decision-makers to establish an IQA. The second key external factor was the increasing perception that the quality of UEM's programmes was decreasing due to rapid expansion and, consequently, the perceived demand for an accountable and high standard HE. But the external factors alone would not have been crucial, had the new leadership at UEM not been engaged. The new rector, appointed in 20II, engaged himself in the establishment and support of the IQA system, as one of the mechanisms for improving quality and tackling fears concerning UEM's potential decline in quality. Unsurprisingly, the objectives ascribed to UEM's IQA system are associated with the need to respond to the demands of external stakeholders, and to tackle the negative perception regarding the quality of HE. The literature reviewed above (Vroeijenstijn, I995; Westerheijden et al. 2007) highlighted two main objectives normally ascribed to a QA system: improvement (I) and accountability (A). UEM's IQA is ascribed six specific objectives, as follows:

- To develop and promote a culture of continuing search for quality (I);

- To assure that the quality of UEM's academic programmes meets the standards required by society and the country's developmental challenges (A);

- To identify and develop quality indicators and respective standards, recognised nationally and internationally (A);

- To identify problems and suggest improvements, by defining policies, drafting and implementing improvement plans, and through resource allocation (I);

- To contribute to capacity-building regarding quality assurance processes within UEM (I);

- To inform society and the country on UEM's academic quality (A) (UEM, 2OI2:3-4).

The categorisation of the six objectives of UEM's IQA system shows a balance: three As and three Is. This balance implies that, at least at policy level, UEM's IQA system has been conceived to promote both improvement and accountability. However, a thorough analysis shows that the three Is are oriented towards UEM's internal stakeholders, whereas the three As are oriented towards external stakeholders. This means that UEM's IQA system aims to promote improvement when oriented inwards, i.e. towards internal stakeholders and processes: to improve the quality of HE, internal processes should be changed and internal stakeholders must drive that process. UEM's IQA system aims to promote accountability when oriented outwards, that is, to external stakeholders: the quality of HE provided should meet the standards defined by external stakeholders.

Unsurprisingly, the main strategies developed to attain the IQA's objectives are concerned with improvement rather than accountability. These strategies include systematic and regular self-assessment at insti- 
tutional and programme levels, the analysis of reports and results, the drafting and implementation of improvements plans, and the establishment of a structural organisation to coordinate the self-assessment, analyse results and implement improvement plans (UEM, 20I2:I2). This organisational structure was also conceived to host external examiners, but its key mission is internal assessment and improvement.

The analysis of the policies of UEM's IQA reveals two challenges facing the system. The first is the omission of a funding strategy (or a lack of clarity concerning funding), both for supporting the IQA system and for linking it to a funding strategy. We will refer later to the financial challenge of running the system; for this subsection, it is relevant to elaborate on the challenge of linking the IQA system to a funding strategy. The documents on policies are not explicit on how the results from quality assessment will be used to financially incentivise those faculties, academic programmes or areas whose quality indicators are good, or to stimulate those with not-so-good indicators. Whatever pros or cons of linking the results of QA to a funding strategy, as examined by Kis (2005: 22-23), we argue that this omission represents a serious challenge for the effectiveness of UEM's IQA system as a steering mechanism for promoting institutional change. As Materu (2007:48) indicates, in Africa, "there is currently no link between QA processes/results and public financing decisions for tertiary education". This challenge is all the more relevant when one considers that UEM approved, in 2013, a new vision to transform itself into a research-led university. How will the IQA system be used as a tool to attain the new vision, and what is the underlying funding strategy? These are relevant questions to address, if UEM's IQA system aspires to be effective.

\section{Structure and Resources}

To achieve the objectives ascribed to UEM's IQA system, an organisational structure was established. The structure was conceived, at least at policy level, to be a semi-autonomous system. As figure 2 below reveals, the IQA unit was designed to be an advisory body for the rector, with its director reporting to the rector. But as an incipient experiment, it was clear that attaining autonomy in the short term was impossible, ineffective and undesirable; for the IQA unit and system to function, direct support from the leadership is a necessity, both in terms of morale and resources. UEM's situation calls for caution when supporting the idea that national and institutional QA units need autonomy to function effectively, as often argued (Hayward, 2006; Materu, 2007; Adamu and Adamu, 20I2). We agree that QA units need autonomy to collect reliable data, make independent analyses and inform unbiased strategic decision-making. However, in the African context, where the QA units often are and will be dependent on government and donor funding, government dependency and support may be less harmful, and even necessary, to the existence of QA systems. At UEM, the IQA structure and system needed to have strong support from the leadership for their survival and sustainability; after gaining legitimacy, the quest for autonomy would then be relevant.

According to Luckett (2006), a QA system may have two roles: collegial-facilitative and bureaucratic-managerial. The first means that the system does not take penalising decisions, but it guides different bodies and faculties to assess their own quality, and it facilitates the assessment process, including the development and implementation of improvement plans. The second penalises faculties and takes decisions on funding. The UEM system has been ascribed a collegial-facilitative role rather than a bureaucratic-managerial one (UEM, 20I3:8). But we argue that, in the medium term, the challenge will be to adopt a managerial role, if the system intends to be an effective steering mechanism to improve quality. And that managerial role, as argued above, implies at least linking the QA's results to a funding policy.

Figure 2. UEM's IQA system/unit's organisational structure (adapted from UEM, 2013: 10)

$$
\text { Rector }
$$

Central University
Bodies $\longrightarrow \begin{aligned} & \text { Internal Quality } \\ & \text { Assurance Unit }\end{aligned} \longrightarrow$ Faculties

Regarding human resources, the central unit worked with the director, an ad-hoc commission of nine academics from different faculties and fields of expertise, including expertise in QA and HE, and a secretariat. At the end of the first year, the ad-hoc commission was dismissed and two of the academics were hired on a part-time scheme. At faculty level, the system was run by a coordinator appointed by the rector (proposed by the dean) and ad-hoc commissions of four to eight members for the self-assessment of programmes. The main challenge regarding human resources was building the capacity of those involved and training them in QA. This challenge confirms previous analyses on African QA systems. Cross-national studies on national QA systems in Africa highlight a lack of personnel familiar with QA issues, including adequately qualified members of peer-review panels (Shabani et al. 
20I4; Materu, 2007; Hayward, 2006). In a recent paper, the findings of Odhiambo (20I4) on the Kenyan HE indicate that there is still a need to train personnel on QA. At UEM, for example, a range of training programmes were, and continue to be, organised, particularly in technical skills, management and leadership for QA implementation, improvement and development.

The other challenge is the financial sustainability of the system. As figures 3 and 4 demonstrate, during the first two years, at central and faculty levels, the system was mainly funded through a donor (Italian Government Project), due to the scarcity of state budget. It is worth mentioning that the decision to allocate these donor funds to a $\mathrm{QA}$ system was taken by UEM's leadership, showing a strong commitment to QA issues. This fact reinforces our earlier argument that strong support from the leadership is important for QA units to be established and to function. The fact that the establishment of UEM's IQA system depended on donor resources may imperil the system's continuity.

UEM's financial challenge is far from being exceptional. Materu (2007) and Hayward (2006) made an inventory of the costs involved in QA across Africa and found out that they were higher than available funds. They also found that, except in wealthier countries such as South Africa, QA costs are mainly supported through international credits or donors. As Materu (2007) indicates, university budgets in Africa hardly include provisions on funding QA. Thus, for QA units to operate effectively and sustainably, QA needs to be considered part of the regular activities of institutions and included in their budgets.

Figure 3. UEM's IQA budget sources: State vs. Italian Project

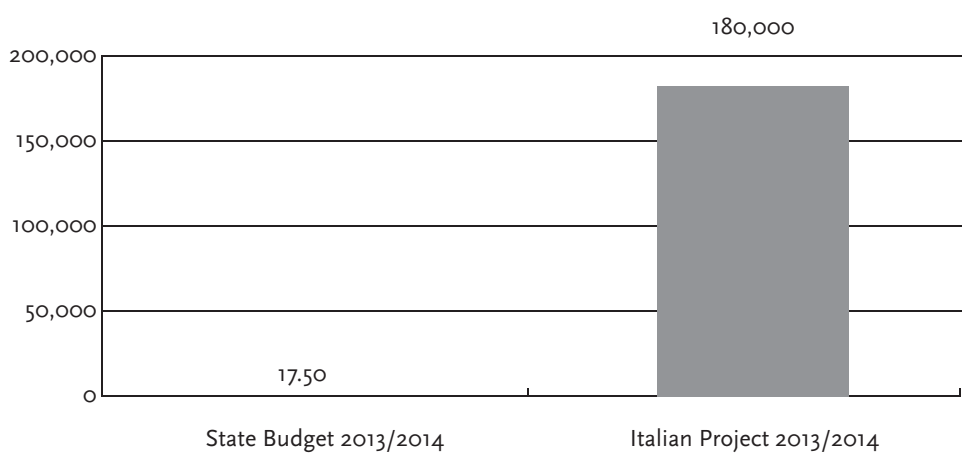

State Budget vs. Italian Project (in Euros)
Figure 4. Used budget vs. balance (in Euros) for 15 faculties 2013/2014

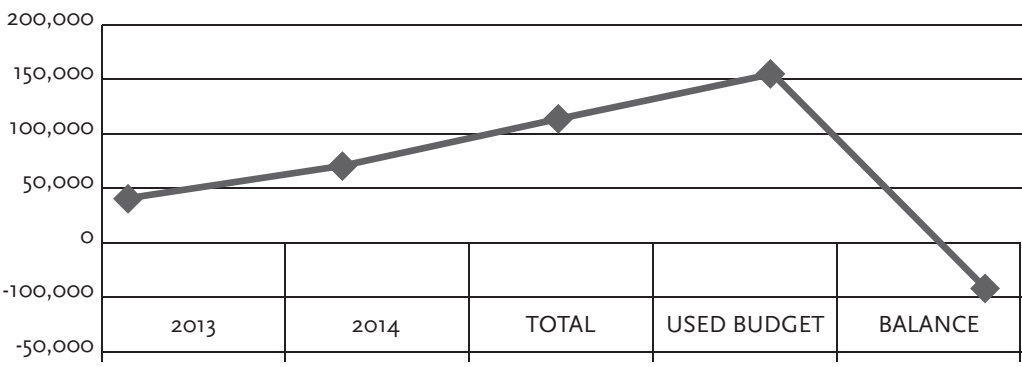

Budget 2013/2014

\section{Processes and Procedures}

As mentioned in the section for policies, UEM's IQA system was designed to promote both institutional improvement and accountability, even if improvement is more emphasised than accountability. The dual role of UEM's IQA system confirms Stensaker (2003)'s argument that boundaries between IQA and EQA may be blurred and both may aim at improving the institution and making it accountable as well. But in the case of UEM's IQA, self-assessment at institutional and programme levels and implementation of improvement plans are more concerned with improvement than accountability (UEM, 20I2:I2).

Strategically, it was decided that, as a first experience, self-assessment would focus only on undergraduate programmes with at least three cohorts of graduates. Thus, I9 undergraduate programmes from I5 faculties were assessed, ranging from humanities to engineering. During the two-year period, several activities were undertaken, including drafting and discussion of the manual for self-assessment of academic programmes (MEA-AP); appointment of quality coordinators and commissions within faculties; outlining activity plans and budgets; carrying out and monitoring course self-assessments; analysis of collected data and writing of self-assessment reports; pilot external evaluation; and drafting of improvement plans. The MEA-AP indicated steps to be followed throughout the process and the areas, and indicators and quality standards to be considered.

The overall approach was inspired from Deming's cycle Plan-DoCheck-Act (Deming, 1986). This approach implied comparing the current situation of the different programmes with quality standards defined in nine domains and I7 sub-domains (table 3), so as to identify 
Table 2. Cycle or phases of the process of IQA at UEM for academic programmes assessment

\begin{tabular}{|c|c|c|c|c|c|c|c|c|c|c|c|c|}
\hline Phases & & & & & & & & & & & & \\
\hline Activities & A & M & J & J & A & $\mathbf{s}$ & 0 & $\mathbf{N}$ & D & 1 & $\mathbf{F}$ & M \\
\hline Phase 1 . Planning and preparation & & & & & & & & & & & & \\
\hline Warm-up and mobilisation & & & & & & & & & & & & \\
\hline $\begin{array}{l}\text { Appointment of self-assessment } \\
\text { commissions }\end{array}$ & & & & & & & & & & & & \\
\hline Outlining of activities plans and budget & & & & & & & & & & & & \\
\hline $\begin{array}{l}\text { Preparation of questionnaires for } \\
\text { administration }\end{array}$ & & & & & & & & & & & & \\
\hline Training of commission members & & & & & & & & & & & & \\
\hline Training of data-clerks & & & & & & & & & & & & \\
\hline Phase 2. Data collection & & & & & & & & & & & & \\
\hline Collection of internal information & & & & & & & & & & & & \\
\hline $\begin{array}{l}\text { Questionnaires administration to } \\
\text { professors, students, administrative } \\
\text { staff }\end{array}$ & & & & & & & & & & & & \\
\hline $\begin{array}{l}\text { Questionnaires administration to } \\
\text { graduates and employers }\end{array}$ & & & & & & & & & & & & \\
\hline Data entry & & & & & & & & & & & & \\
\hline Phase 3. Data and SWOT analysis & & & & & & & & & & & & \\
\hline Questionnaires/survey data analysis & & & & & & & & & & & & \\
\hline Documentary evidence analysis & & & & & & & & & & & & \\
\hline Numerical indicators analysis & & & & & & & & & & & & \\
\hline SWOT analysis & & & & & & & & & & & & \\
\hline Phase 4. Self-assessment report writing & & & & & & & & & & & & \\
\hline First draft writing & & & & & & & & & & & & \\
\hline $\begin{array}{l}\text { First draft presentation to professors, } \\
\text { students and administrative staff }\end{array}$ & & & & & & & & & & & & \\
\hline Draft sending to IQA unit & & & & & & & & & & & & \\
\hline Report discussion by the collegial bodie & & & & & & & & & & & & \\
\hline Final draft writing & & & & & & & & & & & & \\
\hline $\begin{array}{l}\text { Final report sending to IQA unit after } \\
\text { deans' approval }\end{array}$ & & & & & & & & & & & & \\
\hline $\begin{array}{l}\text { Final report sending to external } \\
\text { evaluation }\end{array}$ & & & & & & & & & & & & \\
\hline Phase 5. Improvement plans writing & & & & & & & & & & & & \\
\hline Phase 6. Diffusion & & & & & & & & & & & & \\
\hline $\begin{array}{l}\text { Phase } 7 \text {. Overall assessment of the self- } \\
\text { assessment process }\end{array}$ & & & & & & & & & & & & \\
\hline
\end{tabular}

Source: Santos et al. (2014:16) the programmes' strengths, weaknesses, opportunities and threats. This assessment would result in improvement plans. The implementation of the improvement plans would lead to a new cycle of assessment, SWOT analysis and new improvement plans and so on. After two years of the process, and as a result of a reflection-on-action, several stakeholders agreed that each cycle of academic programme self-assessment would last for a year and would entail seven phases (table 2). Among these phases, the most critical would be data collection, data analysis, report writing and preparation of improvement plans. These phases are crucial for the IQA system to achieve its main objective of improving the quality of UEM's offer of education.

The MEA-AP was the main instrument used for the self-assessment of programmes and it was drafted by the central IQA unit, observing the national guidelines defined by SINAQES and CNAQ. In line with the CNAQ (2OI3) manual, the MEA-AP assessed academic programmes considering nine domains (table 3). Overall, UEM's IQA system adopted a holistic and input-process-output approach, similar to the framework of Shabani et al. (20I4). As table 3 reveals, the Mozambican QA agency identified elements and sub-elements of inputs (students and academic staff), processes (academic management) and outputs (graduates), and defined minimum standards for each element. These elements and standards were used by UEM's IQA unit to draft the MEA-AP. Thus, despite UEM's new vision of becoming a research-led institution, UEM's central IQA unit adopted a holistic paradigm rather than emphasising research, although research is often privileged by international ranking systems (Shabani et al. 20I4; Van Vaught and Ziegele, 2012).

The implementation of UEM's IQA system raised two main challenges regarding the self-assessment of academic programmes. One concerns instruments and another is about the process. The challenge of instruments is related to the nature of the CNAQ standards. For each of the nine domains and I7 sub-domains (table 3 above), CNAQ defined quality standards to be achieved by HEIs. But CNAQ only provided assessment areas and quality standards; it did not provide indicators, nor did it guide HEIs on the kind of data to collect and ways to analyse them, to decide whether a particular academic programme met specific standards. Shabani et al. (2014) and Okebukola and Shabani (2007) suggest that, given the incipient and diversified nature of African HE systems, national QA systems should define minimum standards to be used for each element of QA. But in the case of Mozambique, it is difficult to say whether the CNAQ standards are minimalist or not. Since they are ambiguous, qualitative rather than quantitative, and 
cannot be operationalised, they represent a serious challenge for the HEIs. As table 4 below exemplifies, UEM attempted to make the CNAQ standards operational, more objective, and appropriate for performance classification, but this attempt was not always easy. For example, in the domain of infrastructures, it proved difficult to determine qualitatively and quantitatively the quality standards of labs for medicine, engineering, natural sciences and humanities. Clearly, different standards were required, but defining them accurately was challenging. The performance classification, presented in the footnotes of table 4 , reveals that UEM took a minimalist approach, as suggested by Shabani et al. (20I4). But the intention is to establish more demanding criteria for performance classification, as the system evolves.

Table 3. Areas covered by the self-assessment of UEM's academic programmes

\begin{tabular}{|c|c|}
\hline Domain & Sub-domain \\
\hline \multicolumn{2}{|l|}{ 1. Mission } \\
\hline \multirow{2}{*}{$\begin{array}{l}\text { 2. Academic and quality } \\
\text { management }\end{array}$} & 2A. Academic programme management \\
\hline & 2B. Mechanisms for QA \\
\hline \multirow{4}{*}{ 3. Curriculum } & 3A. Course designation, structure and curricular content \\
\hline & 3B. Teaching-learning process \\
\hline & 3C. Graduates' integration in labour market \\
\hline & 3D. Partnership for curriculum implementation \\
\hline \multirow{4}{*}{ 4. Students } & 4A. Students' profile \\
\hline & 4B. Students' admission \\
\hline & 4C. Students' academic performance \\
\hline & 4D. Social and learning environment \\
\hline \multirow{3}{*}{ 5. Academic staff } & 5A. Academic staff's team \\
\hline & 5B. Academic staff's qualifications and nature of contract \\
\hline & 5C. Procedures for recruiting and managing academic staff \\
\hline \multirow{2}{*}{ 6. Research and outreach } & 6A. Academic programmes research activities \\
\hline & 6B. Academic programmes outreach activities \\
\hline \multicolumn{2}{|l|}{ 7. Administrative staff } \\
\hline \multirow{2}{*}{ 8. Infrastructure } & 8A. Physical infrastructure \\
\hline & 8B. Materials and equipment \\
\hline 9. Internationalisation & \\
\hline
\end{tabular}

Source: UEM (2014: 10) adapted from CNAQ (2013)
Table 4. Operationalisation of the CNAQ (2013) manual (the table exemplifies only one domain and one standard)

\begin{tabular}{|l|l|l|l|l|l|}
\hline $\begin{array}{l}\text { Standards } \\
\text { defined by CNAQ }\end{array}$ & \multicolumn{3}{|l|}{ Operational dimensions added in the UEM manual } \\
\hline Standard & Indicator & Evidence & $\begin{array}{l}\text { Tools for data } \\
\text { collection and } \\
\text { organisation }\end{array}$ & $\begin{array}{l}\text { Evidence } \\
\text { found }\end{array}$ & $\begin{array}{l}\text { Performance } \\
\text { classification }\end{array}$ \\
\hline $\begin{array}{l}\text { 5B.1 Does the } \\
\text { programme have } \\
\text { experienced } \\
\text { academic staff } \\
\text { linked to the } \\
\text { faculty for at } \\
\text { least three years }\end{array}$ & $\begin{array}{l}\text { 5B.1.1. } \\
\text { percentage } \\
\text { of academic } \\
\text { staff per } \\
\text { years of } \\
\text { experience }\end{array}$ & $\begin{array}{l}\text { Contract } \\
\text { signed }\end{array}$ & $\begin{array}{l}\text { Documentary } \\
\text { analysis }\end{array}$ & & 1 \\
\hline
\end{tabular}

Source: Santos et al. (2014: 38), adapted from CNAQ (2013)

The other challenge was the participation of different stakeholders. Two categories of stakeholders participated in the process, those internal to UEM (leaders, academics, technical-administrative staff, students) and those external to UEM (graduates, employers, donors and CNAQ). Their participation was different: leaders (e.g. rector, vicerectors, deans of faculties) participated in decision-making; managers (e.g. heads of department, staff) carried out the self-assessment and participated in the survey; students, graduates and employers participated in the survey; donors provided funds; and CNAQ provided guidelines and supervised the pilot external evaluation. Overall, the participation of internal stakeholders was satisfactory: about 40 percent of the total population of students and academics of the self-assessed programmes were surveyed. This contrasts with the situation of other countries, such as Ghana, where in some HEIs the involvement of students is ineffective (Ntim, 20I4). The absence of an alumni database and of a culture of systematic consultation with the labour market made surveys of graduates and employers challenging. The majority of programmes traced less than 20 percent of the total number of graduates, and only six programmes were successful in surveying employers. 


\section{Quality Results: Features and Challenges}

The self-assessment exercise produced I9 reports. Based on these reports, a comprehensive report was produced to inform the university community on the global results and suggest recommendations for improvement (Santos et al. 20I4). This section provides an overall analysis of the global quality results of the self-assessed programmes. The intention is not to provide a detailed analysis of all results (for a comprehensive report, see Santos et al., 20I4), but to highlight major traits and challenges. For that purpose, we use input-process-output framework of Shabani et al. (20I4): for inputs, we selected some data of curriculum, academic staff and facilities; for process, we selected teaching and management; and for outputs, graduates and employers. The results follow the limitations of the sample. In 20I3, UEM offered I33 programmes ( 40 postgraduate and 93 undergraduate). Only I9 ( 20 percent) of the 93 undergraduate programmes were self-assessed. Despite this percentage, we argue that the sample is representative, given the involvement of I5 of the I7 UEM faculties. Another limitation is the lack of data: not all programmes were able to collect quantitative and qualitative data. Some were unable to survey graduates and employers; others did not obtain statistics or other sort of necessary evidence. For this reason, not all figures include results from the ig programmes.

Some results on inputs: curriculum, academic staff and facilities

Figures 5, 6 and 7 portray features of UEM curriculum, academic staff and facilities. Figure 5 discloses the rigidity of the UEM undergraduate curriculum: about 60 percent of subjects are core, whereas 40 percent are complementary/optional subjects, professional practice, internships and culmination. The UEM curriculum provides few choices for students on which to build their academic careers. This lack of flexibility may undermine UEM's capacity to offer relevant programmes. Figure 6 confirms earlier analysis (Cloete et al. 2015) on the fragile qualifications of academic staff and the weak propensity for knowledge production in Africa, measured in terms of $\mathrm{PhD}$ holders: about 70 percent of the academic staff do not hold a $\mathrm{PhD}$. This situation is a challenge for UEM's quality of teaching and research, as elsewhere in Africa (Okebukola, 20I5). Figure 7 adds up to this dark portrait: about 70 percent of the students are not satisfied with facilities. This means that facilities have to be improved, particularly facilities with a direct impact on the quality of teaching and research, such as literature, labs, computers and internet.
Figure 5. Curriculum structure

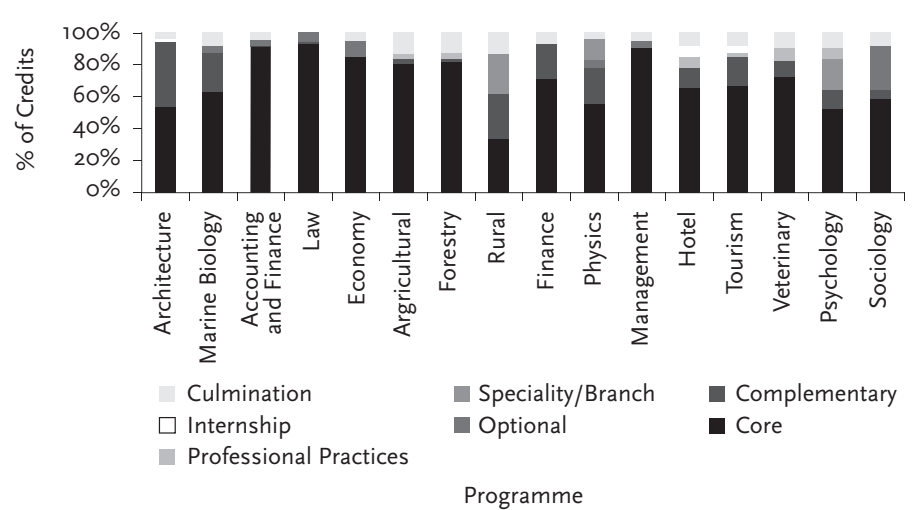

Figure 6. Qualifications of academic staff

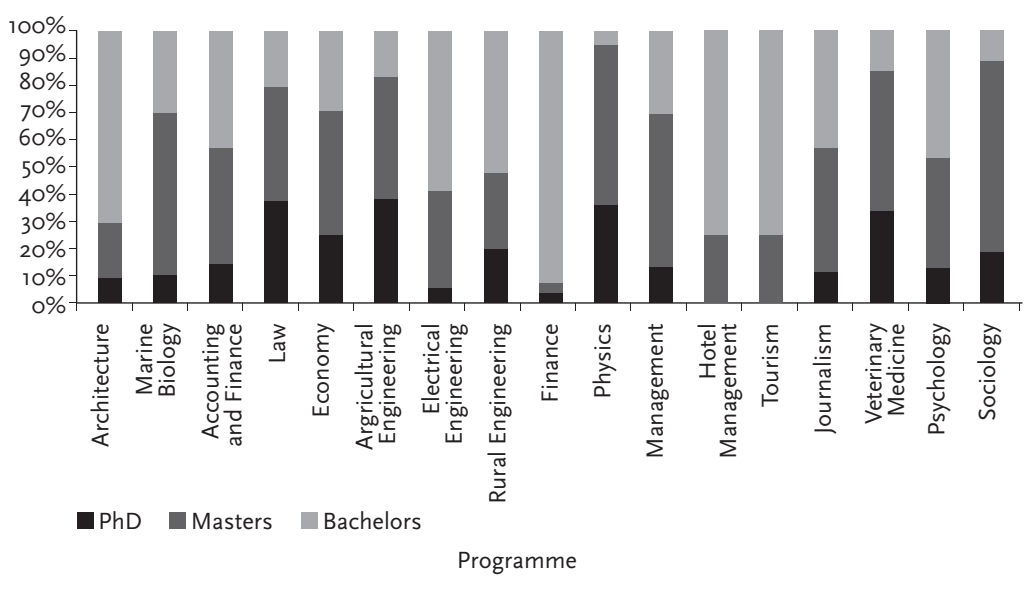

Some results on process: teaching-learning process and management Figure 8 reveals that about 90 percent of graduates consider teaching methods at UEM theoretical and only about 30 percent indicate professional internships and dramatisation as the methods used. Regarding some management indicators, figures 9 and ro depict a situation of dissatisfaction: less than 20 percent of students are satisfied with the socio-academic support (figure 9) and about 30 percent of the academic staff are satisfied with their working conditions, particularly professional development and conditions provided for teaching and research. 
Figure 7. How satisfied are you with the following facilities of the programme? (1816 from 17 programmes)

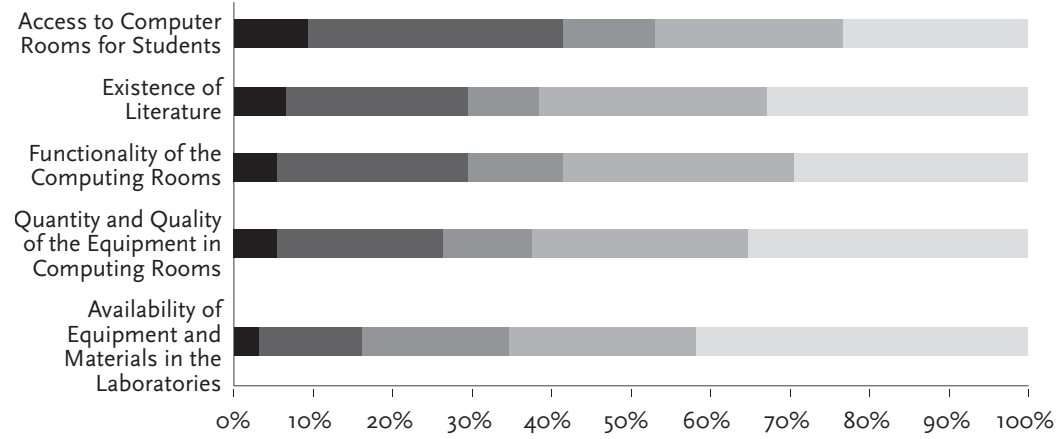

$\begin{array}{ll}\text { Very Satisfied } & \text { Neutral } \\ \text { Satisfied } & \text { Slightly Unsatisfied }\end{array}$

Figure 8. To what degree were the following teaching methods applied by the lecturers (289 graduates from 13 programmes)?

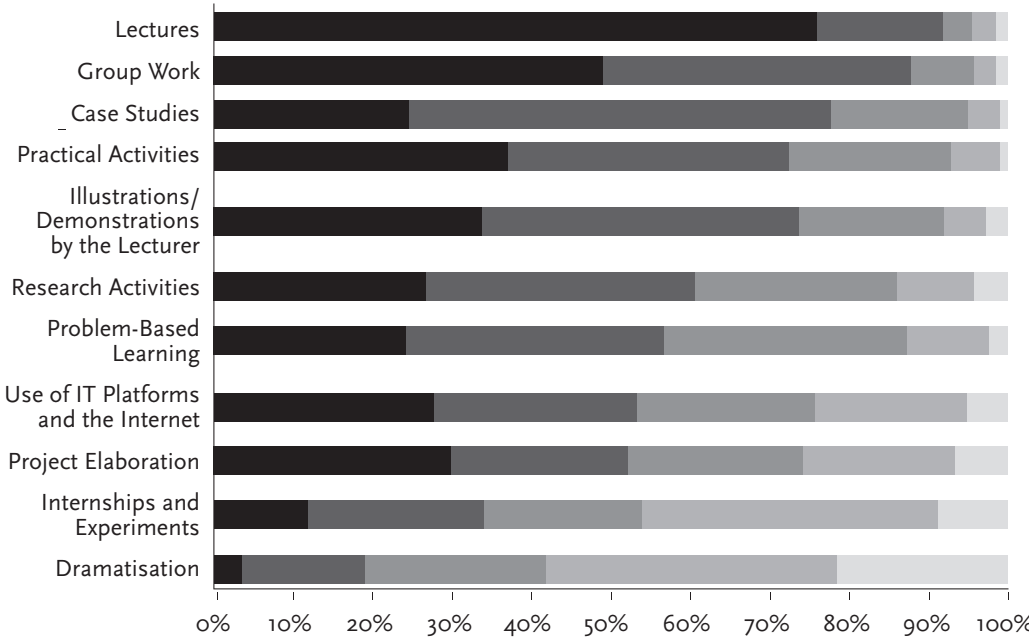

Some results on outputs: graduates' employability

Contrary to the dark portrait of some inputs and processes above, figure II unveils the facility of the professional integration of graduates: more than 80 percent got employment in less than 6 months after completion. And figure 12 shows that employers rate positively the knowledge and skills of UEM graduates, though caution needs to be taken in its interpretation. While the facility of professional integration may be associated with the relevance of programmes, it may also be related to the structure of the Mozambican labour market and to methodological bias, namely the narrow sample of graduates surveyed and the possible fact that only graduates with a relatively stable professional situation were traced.

Figure 9. How satisfied are you with the academic and social support offered to students (1816 students of 17 programmes)?

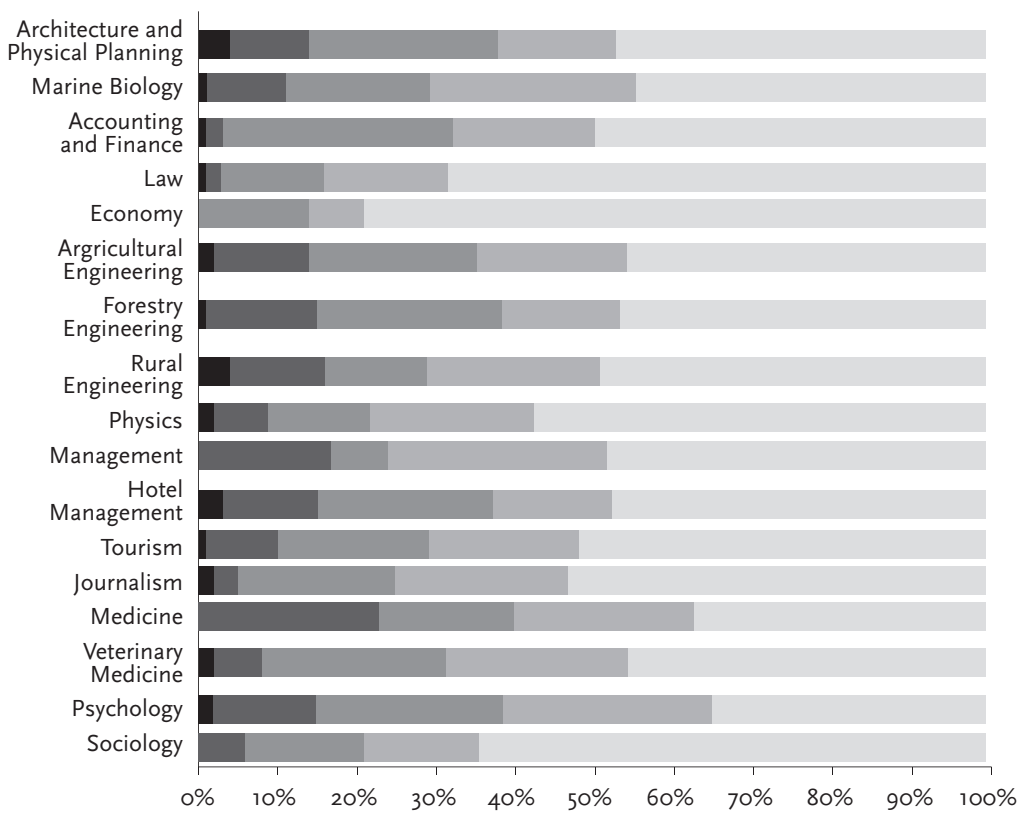

- Very Satisfied $\quad$ Satisfied Neutral Slightly Unsatisfied Unsatisfied

$\begin{array}{ll}\text { Always } & \text { A few times } \\ \text { Sometimes } & \text { Never }\end{array}$


Figure 10. How satisfied are you with general conditions of the faculty/school? (311 academic staff from 17 programmes)?

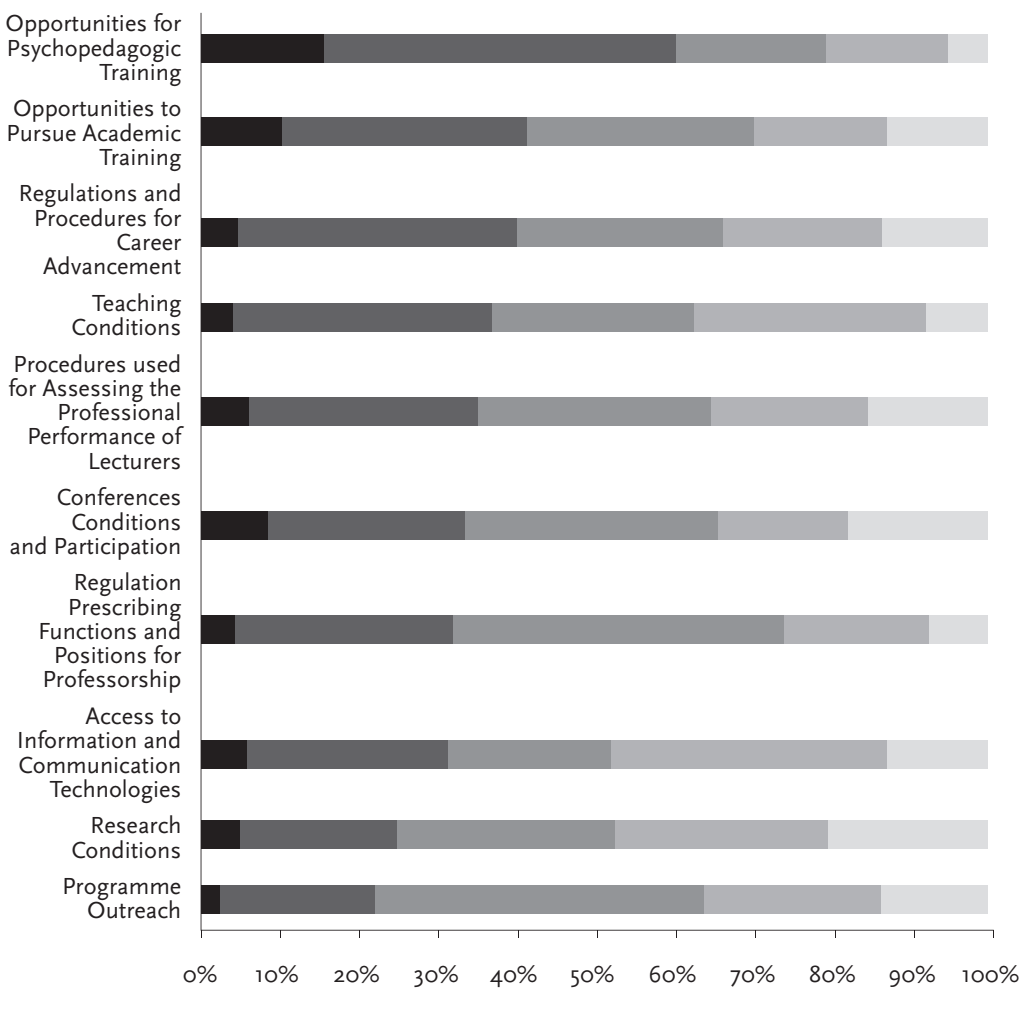

घ Very Satisfied $\quad$ Satisfied Neutral $\quad$ Slightly Unsatisfied Unsatisfied

Figure 11. How long did it take to acquire gainful employment after the conclusion of your programme ( 289 graduates from 13 programme)?

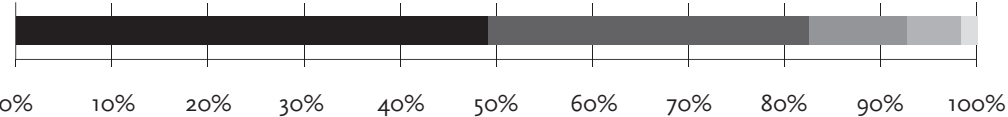

- Immediate $\quad 1-6$ months 7 to 11 months 1 to 2 years More than 2 years
Figure 12. How do UEM graduates score on knowledge, potential and ability (49 employers from 8 programmes)?

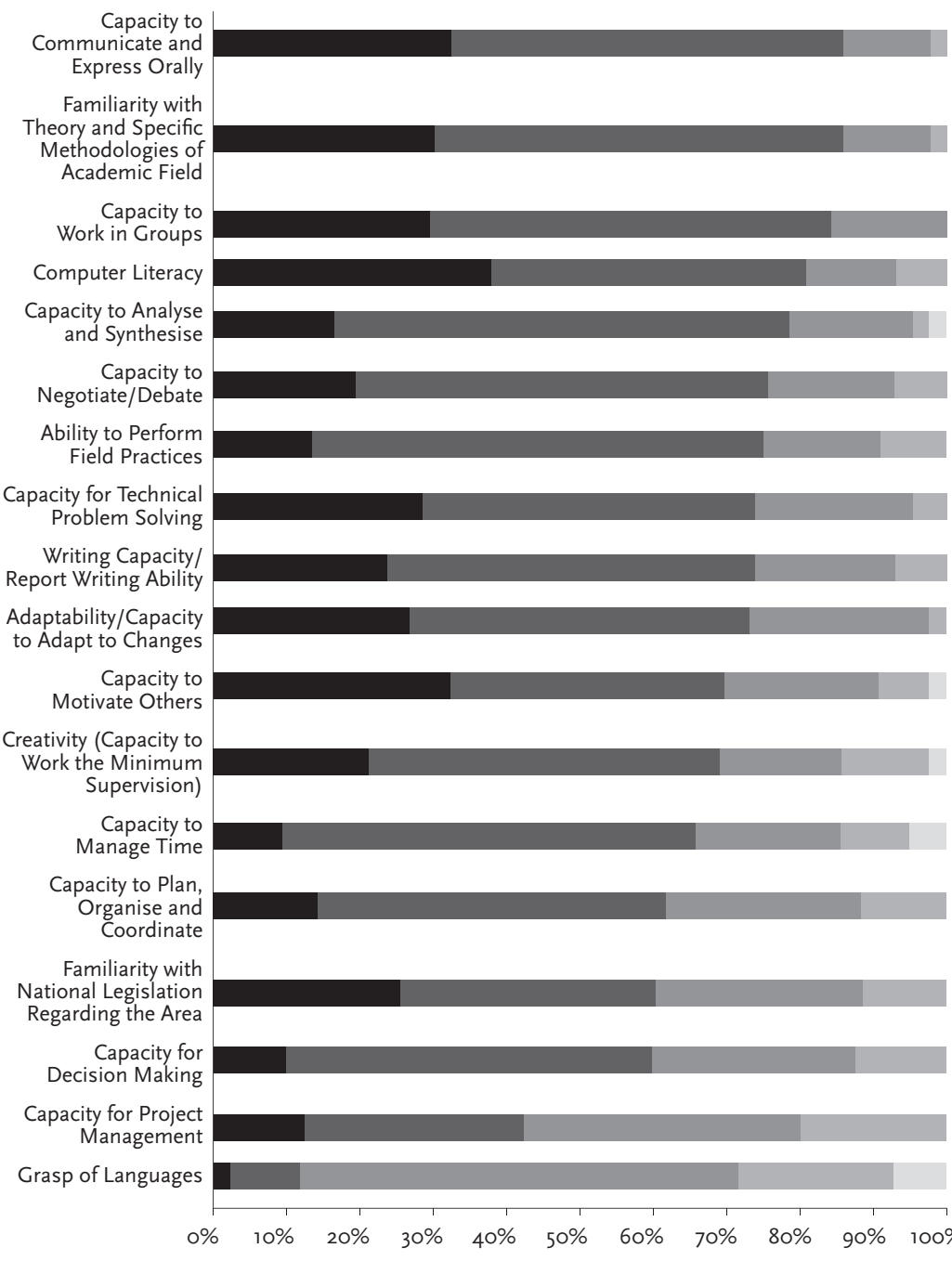

- Very Good G Good $\square$ Average Weak Very Weak 


\section{Challenges Implied by the Results on Quality}

Despite being partial, these results portray the quality of UEM's undergraduate programmes. The aggregate SWOT analysis revealed that (i) experience and national prestige were UEM's main strengths; (ii) teachers qualifications, research-outreach and facilities, its main weaknesses; (iii) the research-led vision, its main opportunity; and (iv) the competitive Mozambican HE landscape, its main threat. Unfortunately, the quality situation at UEM, particularly its weaknesses, still characterises many African countries. According to Okebukola (20I5: 56), depreciating qualifications among the teachers, research capacity deficit and inadequate facilities are among the ro major challenges faced by African HE.

The production and diffusion of these results raised three main challenges. Firstly, the need for a systematic database: the self-assessment disclosed the problem of insufficiency of databases and records at UEM. The problem with the database aggravated the challenge of defining objective and measurable standards. To avoid relying on international metrics, the definition of minimum standards should be context-grounded. But without reliable contextual data, it is difficult to define objective performance standards, as suggested by Shabani et al. (20I4:I45). The second challenge was the propensity of some managers to see results as an individual evaluation, and not as an opportunity for institutional transformation. As Materu (2007) highlighted, one of the major challenges of QA in Africa is its strategic usage for institutional change. This finding is also associated to the third challenge: decisionmaking based on QA results, and their linkage to a funding policy. Having been designed primarily to promote improvement, UEM's IQA system involved implementing improvement plans. But since the system was not linked to a funding strategy from the beginning, concerns were raised regarding financial resources to implement plans. After vivid debates and unfruitful attempts to include improvement plans into the budgets of the faculties, UEM's leadership approved a competitive fund for quality improvement.

\section{Conclusion}

The newly established IQA system at UEM contains four main features: (i) policies; (ii) structures and resources; (iii) processes and procedures; and (iv) results. As a newly established system, it may need to consider the following main issues. First, its facilitative role must be transformed into a managing tool used to improve the university while making it accountable.

Second, equipping the system with human and sustainable financial resources to enable functionality and continuity is paramount. QA costs should be integrated into institutional budgets. Training programmes in QA issues are needed as well to enhance the professional expertise of academic staff per discipline.

The third point is about making the system fully functional and acceptable by the entire university community and by society. For this to happen, the whole university community should be informed of the major goals of QA - improvement and accountability - and all relevant stakeholders, both external and internal, should be involved in the process, particularly in the definition of (measurable) minimum quality standards.

Finally, defining measurable, objective and acceptable quality standards, to enable unbiased and uncontested performance classification, is surely one of the major challenges of UEM's IQA system. UEM will surely not overcome this challenge on its own: rigorous, objective and measurable standards need to be defined at national (by CNAQ) and, perhaps, regional and continental levels, and these standards need to be used for external examination and accreditation.

\section{References}

Adamu, A. and Adamu, A. (2012). Quality Assurance in Ethiopian higher education: procedures and practices. Procedia, 69: 838-846.

Bull, T. et al. (2012) University of Namibia: Evaluation Report. EuropeAfrica Quality Connect.

Botha, J., Fayish, J. Stephenson, S. (2008). Institutional Audits: A Comparison of the Experiences of Three South African Universities, Journal Quality in Higher Education, I4(I): 29-53.

Campbell, C. and Rozsnyai, C. (2002) Quality Assurance and the Development of Course Programmes. Bucharest: UNESCO-CEPES.

CNAQ (20I3) Guião de Auto-Avaliação de Cursos e/ou Programas e Instituições de Ensino Superior em Moçambique. Maputo.

Cloete, N., Maassen, P. and Bailey, T. (eds.) (2015) Knowledge Production and Contradictory Functions in African Higher Education. Cape Town: African Minds.

Deming, Y. (I986) Out of the Crisis. MIT: Centre for Advanced Engineering Study.

Hayward, F. (2006). Quality Assurance and Accreditation of Higher Education in Africa. Conference on Higher Education Reform in Francophone Africa: understanding the Key of Success. June I3-I5, Ouagadougou.

Jegede, O. (20I2) The State of Higher Education in Africa. Weaving Success: Voices of Change in African Higher Education, NY, February I. 
Kahsay, M. N. (2012) Quality and Quality Assurance in Ethiopian Higher Education: Critical issues and practical implications. PhD dissertation, CHEPS/University of Twente.

Kis, V. (2005) Quality Assurance in Tertiary Education: Current Practices in OECD Countries and a Literature Review on Potential Effects. OECD Thematic Review of Tertiary Education.

Lanarès, J. et al. (2012) Kenyatta University: Final Report. Europe-Africa Quality Connect.

Langa, P.V. (20I4a) The roles and functions of higher education councils and commissions in Africa: A case study of the Mozambique's CNAQ. Cape Town: CHET.

Langa, P.V. (20I4b) "Alguns desafios do ensino superior em Moçambique: do conhecimento experiencial à necessidade de produção de conhecimento científico." In De Brito et al. (eds). Desafios para Moçambique 2014. Maputo: IESE, 365-395.

Loukkola, T. and Zang. T. (2010) Examining Quality Culture: Part 1- Quality Assurance Processes in Higher Education Institutions. Brussels: European University Association.

Luckett, K. (2006) The quality assurance of teaching and learning in higher education in South Africa: an analysis of national policy development and stakeholder response. PhD dissertation, University of Stellenbosch.

Mabuza, L. (20I4). Unpacking Quality Assurance Issues in Distance Education: Using the University of South Africa, a Mega Open Distance Learning University as an Example, Journal of Information and Education Technology, 4 (6): 513-516.

Mário, M. et al. (2003) Higher Education in Mozambique. Oxford: James Curry.

Materu, P. (2007) Higher Education Quality Assurance in Sub-Saharan Africa: Status, challenges, opportunities and promising practices. Washington DC: World Bank.

Mohamedbhai, G. (20I4) Massification in Higher Education Institutions in Africa: Causes, Consequences and Responses. International Journal of African Higher Education, I(I): 60-83.

Müller, W. et al. (2012) Ahmadu Bello University: Evaluation Report. Europe-Africa Quality Connect.

Nguyen, T. (2012) Internal Quality Assurance in Vietnams' higher education: the influence by projects. Master Dissertation. CHEPS/ University of Twente.

Ntim, S. (20I4) Embedding quality culture in higher education in Ghana: quality control and assessment in emerging private universities, Higher Education, 68:837-849.
Odhiambo, G. (20I4) Quality assurance for public higher education: context, strategies and challenges in Kenya, Higher Education Research and Development, 33(5): 978-99I.

Odukoya, J. et al. (2015). Quality Assurance Practice in African Universities: Lessons from a private Nigerian University, Journal of Educational and Social Research, 5(2): 25I-260.

Ogachi, A. (2009). Internationalization vs Regionalization of Higher Education in East Africa and the Challenges of Quality Assurance and Knowledge Production, Higher Education Policy, 22:33I-347.

Okebukola, P. (20I5) Higher Education and Africa's Future: Doing What is Right? 1oth Convocation distinguished lecture. Covenant University, June 25 .

Okebukola, P. And Shabani, J. (2007) Quality assurance and accreditation in higher education in Sub-Saharan Africa. In Global University Network for Innovation (GUNI) (Ed.), Higher education in the world 2007: Accreditation for quality assurance-what is at stake? New York: Palgrave Macmillan. 46-59.

Perellon, J. (2007) Analysing Quality Assurance in Higher Education: Proposal for a conceptual framework and methodological implications. In Westerheijden et al. (eds) (2007),I55-I78.

Rosa, M. and Amaral, A. (2007) A self-assessment of Higher Education Institutions from the perspective of the EFQM Model. In Westerheijden et al. (eds) (2007).I8I-207.

Santos, L. et al. (20I4). Relatório Global de Auto-avaliação dos Cursos. Maputo:.http://gqa.uem.mz/images/pdf_files/relatorioglobal2or4.pdf, consulted on 27 May 2015.

Schön, D. A. (I983) The reflective practitioner. Aldershot: Ashgate Arena.

Shabani, J., Okebukola, P. and Oyewole, O. (20I4) Quality Assurance in Africa: Towards a Continental Higher Education and Research Space, International Journal of African Higher Education, I (I): I39I7I

Stensaker, B. (2003) Trance, Transparency and Transformation: the impact of external quality monitoring on higher education, Quality in Higher Education, 9 (2):

Sursock, A. (20II) Examining Quality Culture: Part I1 - Processes, Ownership and Bureaucracy. Brussels: European University Association.

UEM (20I4) Manual de Auto-avaliação dos Cursos. Maputo: UEM/ Imprensa Universitária.

UEM (20I3) Proposta de criação do Gabinete para a Qualidade Académica na UEM. Maputo.

UEM (20I2) Sistema de Garantia de Qualidade Académica da UEM (SISQUAL). Maputo. 
UNESCO Institute for Statistics (20I5) UNESCO data tables. Retrieved on 24 May 20I5, from UNESCO http://data.uis.unesco.org/.

Van Damme, D. (2002) Trends and Models in International Quality Assurance and Accreditation in Higher Education in Relation to Trade in Education Services. Washington: OECD/US Forum on Trade in Educational Services.

Van Vught, F. and Ziegele, F. (eds) (20I2) Multi-dimensional Ranking: the design and development of U-Multi-rank. Higher education Dynamics, Springer, 37.

Van Vught, F. (I995) The next context for academic quality. In Dill, D. and Barbara, Sporn (eds) Emerging Patterns of Social Demand and University Reform: Through a Glass Darkly. Oxford: Pergamon, I942 II.

Van Vught, F. and Westerheijden, D.F. (I994) Towards a General Model of Quality Assessment in Higher Education. Higher Education, 3: 355-37I.

Vlãsceanu, L., Grünberg, L. and Pârlea, D. (2007) Quality Assurance and Accreditation: A Glossary of Basic Terms and Definition. Bucharest: UNESCO-CEPES.

Vroeijenstijn, A. (I995) Improvement and Accountability: navigating between Scylla and Charybdis. Guide for external quality assessment in higher education. London: Jessica Kingsley Publications.

Westerheijden, D. et al. (eds.) (2007) Quality Assurance in Higher Education: Trends in regulation, translation and transformation. Springer, Dordrecht. 